\title{
Síndrome do anticorpo antifosfolípide causando oclusão bilateral de artérias e veias centrais da retina: relato de caso
}

\author{
Antiphospholipid syndrome and bilateral retinal artery and vein occlusion: \\ case report
}

\author{
Ana Paula Beckhauser ${ }^{1}$ \\ Luís Augusto Arana ${ }^{2}$ \\ Thelma Larocca Skare ${ }^{3}$
}

Trabalho realizado no Departamento de Reumatologia do Hospital Universitário Evangélico de Curitiba e no Hospital de Olhos de Curitiba - Curitiba (PR) - Brasil.

${ }^{1}$ Médica residente em clínica médica do Hospital Universitário Evangélico de Curitiba - HUEC - Curitiba (PR) - Brasil

${ }^{2}$ Médico residente do Hospital de Olhos de Curitiba Curitiba (PR) - Brasil.

${ }^{3}$ Chefe do serviço de Reumatologia do HUEC - Curitiba (PR) - Brasil.

Endereço para correspondência: Ana Paula Beckhauser. R. Nunes Machado, 471 - Apto. 402 - Curitiba (PR) CEP 80250-000 - E-mail: anabeckh@hotmail.com

Recebido para publicação em 26.07.2006

Última versão recebida em 25.09.2007

Aprovação em 07.11.2007

\begin{tabular}{|l|}
\hline RESUMO \\
\hline A síndrome do anticorpo antifosfolípide (SAF) tem sido associada a \\
trombose de vasos arteriais e periféricos e de grande ou pequeno calibre. \\
Também os vasos oculares estão sujeitos à ação destes auto-anticorpos \\
que podem promover o aparecimento de perda visual transitória, diplopia, \\
neuropatia óptica isquêmica e oclusão de artéria ou veia da retina. É \\
descrito aqui, um caso de síndrome do anticorpo antifosfolípide com \\
oclusão de vasos centrais arteriais e venosos da retina no intuito de chamar \\
a atenção para este tipo de diagnóstico.
\end{tabular}

Descritores: Anticorpos anticardiolipina; Oclusão da veia retiniana; Veia retiniana; Humano; Feminina; Adulto; Relatos de casos [Tipo de publicação]

\section{INTRODUÇÃO}

Os anticorpos antifosfolípides formam uma classe heterogênea de imunoglobulinas circulantes associadas a estados de hipercoagulabilidade que se manifestam como tromboses recorrentes ${ }^{(1-2)}$. Neste grupo de anticorpos incluem-se os anticardiolipinas $(\mathrm{aCl})$, o anticoagulante lúpico (LAC), anticorpos contra fosfatidilinositol, fosfatidilserina e fosfatidiletolamina entre outros ${ }^{(1-2)}$. Destes, os dois primeiros, aCls e LAC, são os mais comuns ${ }^{(1)}$.

Os anticorpos antifosfolípides são encontrados em uma grande variedade de situações podendo, inclusive, ser achados em pessoas normais nas quais se constituem apenas numa anormalidade bioquímica, ou seja, não têm repercussão patológica. Mais comumente estão associados ao lúpus eritematoso sistêmico, mas também são encontrados em pacientes com outras colagenoses ou, mesmo isoladamente, numa forma clínica conhecida como síndrome do anticorpo antifosfolípide (SAF) primária ${ }^{(2)}$. Desta maneira observa-se que, para que um paciente seja considerado portador de SAF, não basta a simples detecção de um destes auto-anticorpos circulantes mas, este deve exercer atividade pró-coagulante, a qual pode se manifestar das maneiras mais variadas possíveis. Achados compatíveis com este diagnóstico são os de tromboses arterial e/ou venosa recorrentes, VDRL falso positivo, perdas fetais de repetição, trombocitopenias, livedo reticularis, anormalidades cardíacas valvulares e acidentes vasculares encefálicos ${ }^{(3-4)}$.

O quadro clínico, como pode ser notado, é extremamente proteiforme e, por envolver diferentes aparelhos e sistemas, infiltra-se no diagnóstico diferencial das doenças de quase todas as especialidades médicas, inclusive a oftalmologia. 
Neste artigo iremos descrever um caso de síndrome do anticorpo antifosfolípide primária que se manifestou inicialmente com trombose de vasos da retina (artéria e veia centrais) no sentido de alertar a comunidade médica para este tipo de enfermidade que, além de causar grandes prejuízos para a qualidade de vida do seu portador, pode também ameaçar a sua sobrevida.

\section{RELATO DE CASO}

Paciente feminina, 27 anos, procura o pronto atendimento com queixa de dispnéia de início há 8 dias associado à tosse seca. Foi tratada com inalações e broncodilatadores, sem melhora. Cerca de $24 \mathrm{~h}$ antes haviam surgido escotomas no campo visual direito, seguidos por perda da visão neste olho. Procurou atendimento oftalmológico tendo sido diagnosticado oclusão da veia central da retina à direita.

$\mathrm{Na}$ história pregressa existiam 3 gestações com 2 abortamentos e uma história de trombose de membro inferior esquerdo 15 dias após o único parto. A paciente fazia uso de anticoncepcional injetável (medroxiprogesterona) e não era fumante.

O exame físico mostrava uma jovem hipocorada, hidratada, taquipneica, com midríase paralítica e amaurose à direita. Sinais vitais mostravam pressão arterial de $120 \times 80$, pulso de $110 \mathrm{bpm}$, temperatura $=37,8^{\circ} \mathrm{C}$; freqüência respiratória de $24 / \mathrm{min}$. O restante do exame físico era normal.

Uma radiografia de tórax mostrou consolidações em base direita e uma gasometria arterial evidenciou hipoxemia (pO2 $=58,3 \mathrm{mmHg}$ ). O eletrocardiograma era normal. O hemograma mostrava anemia $(\mathrm{VG}=26,2 \%)$ e plaquetopenia de 147.000. A série branca era normal. CPK e Ck-mb eram nor-
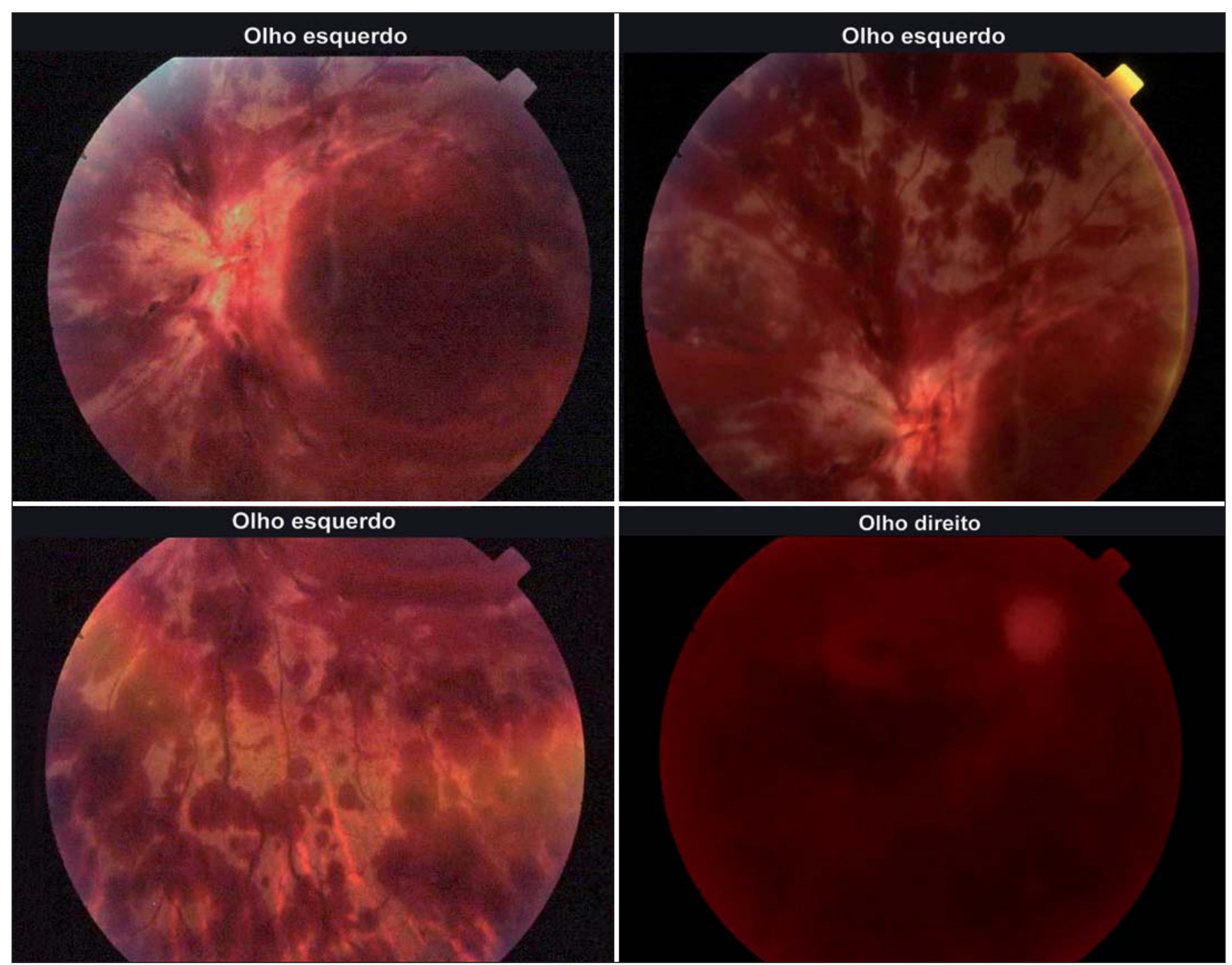

Figura 1 - Retinografia da paciente descrita. Ambos os olhos: disco óptico com bordas borradas e hemorragias epi e peridiscais; hemorragias retinianas profundas, superficiais e pré-retinianas nos quatro quadrantes; dilatação venosa generalizada; olho direito: hemorragia vítrea associada; olho esquerdo: vasos hialinizados no pólo posterior; placas hemorrágicas intra-retinanas profundas. 
mais e o KPTT, de 55,8 segundos. Uma tomografia de crânio também foi normal.

A paciente foi internada com diagnóstico de tromboembolismo pulmonar e oclusão de veia central da retina, sendo prescrito heparina de alto peso molecular endovenosa seguida de cumarínicos orais e sintomáticos.

No oitavo dia de internamento, a paciente evoluiu com perda súbita da visão do olho esquerdo. Foi feita nova avaliação oftalmológica com diagnóstico clínico de oclusão de veia central da retina esquerda. Recebeu, na época, heparina endovenosa em bolo, AAS e pulsoterapia com corticóide. Todavia não se observou melhoria na acuidade visual e a paciente permaneceu apenas com percepção de luminosidade em OE.
Exames realizados durante internamento mostraram: fator antinuclear e fator reumatóide: não reagentes; dosagem de C3: 10,10 mg/dl (valor normal entre 16 - $45 \mathrm{mg} / \mathrm{dl}$ ); C4: 105 $\mathrm{mg} / \mathrm{dl}$ (valor normal entre 70 - $176 \mathrm{mg} / \mathrm{dl}$ ); VHS: $97 \mathrm{~mm}$ na $1^{\mathrm{a}}$ hora; HIV: não reagente; VDRL: reagente até título de 1/4; FTA-ABS: IgG e IgM não reagentes; ressonância magnética de crânio normal; ecocardiograma, normal. Ecodoppler de membros inferiores mostrou trombose venosa em membro inferior esquerdo e trombose de veia cava inferior até emergência de veia renal esquerda. Angiofluoresceinografia retiniana mostrou oclusão de veia e artéria central da retina bilateralmente (Figuras 1 e 2). Anticorpos anticardiolipinas IgG foram positivos em títulos $>120 \mathrm{UI} / \mathrm{ml}$ (normal até $10 \mathrm{UI} / \mathrm{ml}$ ), os
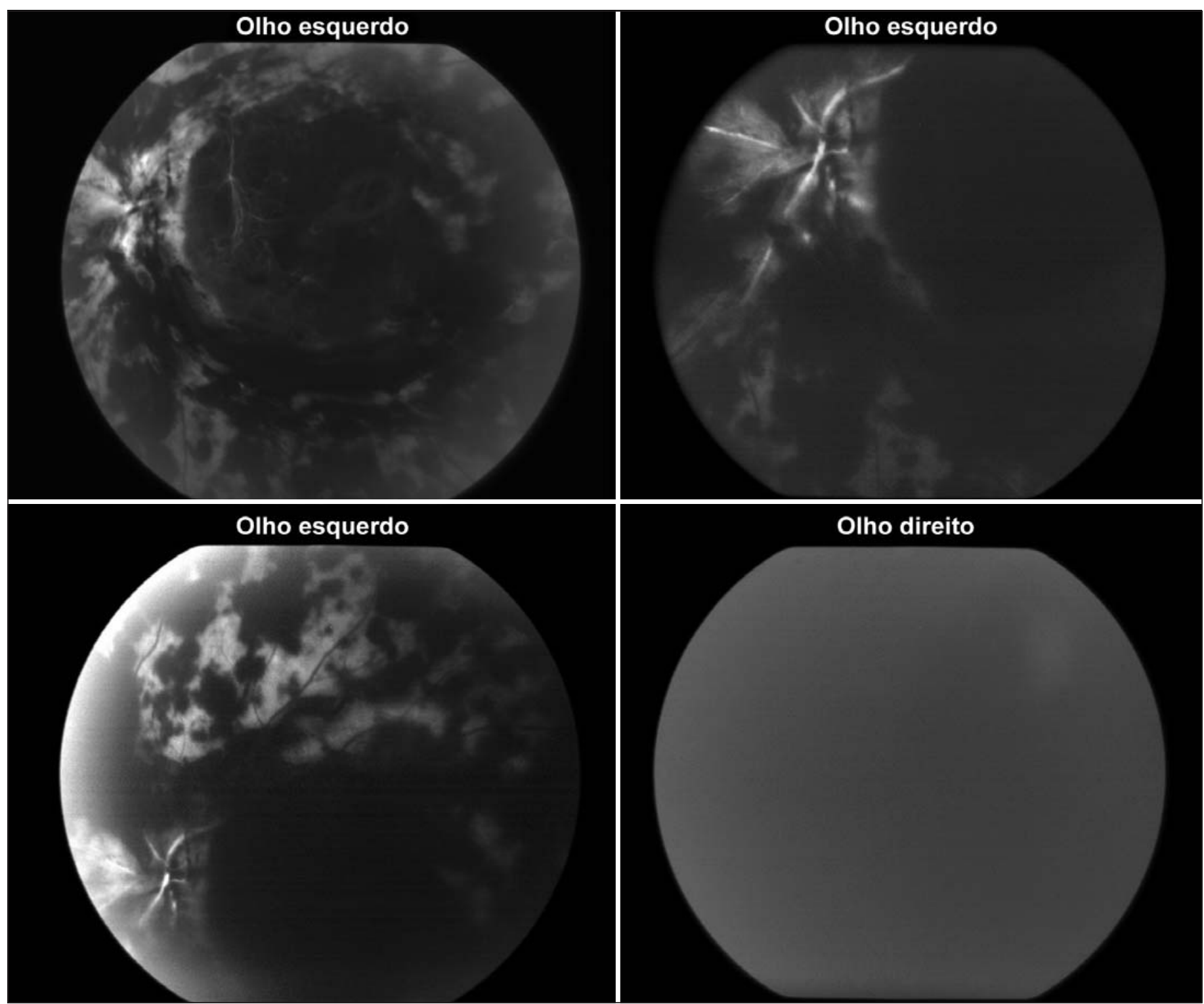

Figura 2 - Retinografia fluoresceínica da paciente descrita. Ambos os olhos: não há perfusão arterial e venosa nos quatro quadrantes retinianos; olho direito: exame prejudicado pela turvação de meios; contudo, observa-se discreta hiperfluorescência no disco óptico nas fases tardias; olho esquerdo: observa-se pequena perfusão arterial no disco óptico. Impressão diagnóstica: oclusão arterial e venosa central bilateral. 
anticardiolipinas IgM foram negativos $(6,25 \mathrm{UI} / \mathrm{ml})$ e anticoagulante lúpico foi positivo com valor de 121 segundos (normal de 29 - 51 segundos).

Com diagnóstico de síndrome do anticorpo antifosfolípide primária a paciente permaneceu em tratamento com AAS e cumarínico (mantendo-se o RNI entre 3,0 e 4,0) sendo adicionado o uso de cloroquina. Recebeu alta com melhora da dispnéia, permanecendo amaurótica à $\mathrm{D}$ e com percepção luminosa à E.

\section{DISCUSSÃO}

A SAF é uma síndrome de hipercoagulabilidade que afeta vasos venosos ou arteriais, embora - de maneira distinta de outras síndromes de hipercoagulabilidade - tenha uma maior prevalência de trombose $\operatorname{arterial}^{(5)}$.

São poucos os relatos de SAF primária associados à doença ocular, mas têm sido descritos casos de perda visual transitória, diplopia, neuropatia óptica isquêmica e oclusão de artéria ou veia da retina ${ }^{(6)}$.

Existem vários mecanismos propostos para explicar como estes auto-anticorpos promovem trombose. A primeira hipótese é a de que ocasionem ativação das células endoteliais ${ }^{(7-9)}$. A ligação dos aCl com estas células promove aumento na expressão de moléculas de adesão, secreção de citocinas e metabolismo das prostaglandinas, favorecendo a produção de tromboxane A2 que é um agente agregante plaquetário sobre a produção de prostaciclina (que é um agente vasodilatador) ${ }^{(7,10)}$.

Uma segunda teoria prevê que causem injúria vascular acelerando a aterogênese. A reação cruzada de anticorpos antifosfolípides com colesterol LDL oxidado favorece a captação deste tipo de colesterol pelos macrófagos que irá formar a célula espumosa que, por sua vez, é o nicho inicial da placa aterosclerótica ${ }^{(7)}$.

Uma terceira teoria propõe que estes anticorpos interferem com anticoagulantes séricos naturais, neutralizando-os. Entre estes anticoagulantes naturais está a anexina V, proteína $\mathrm{C}$, S e a $\beta 2$ glicoproteina $\mathrm{I}^{(7)}$.

Estes mecanismos propostos não são mutuamente exclusivos podendo existir uma superimposição dos mesmos.

A presença de altos títulos de anticardiolipina $\operatorname{IgG}(>40$ UI), como no caso descrito, é o elemento preditor mais fortemente relacionado a tromboses ${ }^{(8)}$. Além disto, altos níveis de $\mathrm{aCl}$ aumentam o risco de trombose recorrente, conforme descrito por alguns autores ${ }^{(4)}$. Nestes casos, a trombose pode ocorrer mesmo na vigência da queda dos títulos destes anticorpos porque esta queda pode ser devida ao seqüestro dos mesmos pelo trombo ${ }^{(4-5)}$.

Observe-se que, no caso acima, houve recorrência de eventos oculares na vigência de doses adequadas de anticoagulante. O risco de repetição de um evento trombótico oscila de 7,1 a 10,7\% ao ano em pacientes que estão recebendo tratamento apropriado ${ }^{(11)}$.

Devido ao fato de esta doença apresentar-se com alta morbidade como a verificada no caso descrito e, por ter alta mortalidade (de até 40 - 50\%) quando se apresenta na forma catastrófica (com tromboses em vários órgãos) ${ }^{(10)}$, ressalta-se a importância do diagnóstico correto e tratamento adequado desta condição.

\section{ABSTR ACT}

The antiphospholipid syndrome (APS) has been related to venous and arterial thrombosis of large and small vessels. Ocular vessels can also be involved causing transient visual loss, diplopia, ischemic optic neuropathy and central artery and venous occlusion. We describe here a case of antiphospholipid syndrome with occlusion of central retinal artery and vein to call the attention to this diagnosis.

Keywords: Antibodies, anticardiolipin; Retinal vein occlusion; Retinal vein; Human; Female; Adult; Case reports [Publication type]

\section{REFERÊNCIAS}

1. Provenzale JM, Ortel TL, Allen NB. Systemic thrombosis on patients with antiphospholipid antibodies: lesion distribution and imaging findings. AJR Am J Roentgenol. 1998;170(2):285-90.

2. Asherson RA, Merry P, Acheson JF, Harris EN, Hughes GR. Antiphospholipid antibodies: a risk factor for occlusive ocular vascular disease in systemic lupus erythematosus and the 'primary' antiphospholipid syndrome. Ann Rheum Dis. 1989;48(5):358-61. Comment in: Ann Rheum Dis. 1990;49(3):203.

3. Provenzale JM, Ortel TL. Anatomic distribution of venous thrombosis on patients with antiphospholipid antibody: imaging findings. AJR Am J Roentgenol. 1995;165(2):365-8.

4. De Godoy JM, de Godoy MF, Braile DM. Recurrent thrombosis in patients with deep vein thrombosis and/or venous thromboembolism associated with anticardiolipin antibodies. Angiology. 2006;57(1):70-83.

5. Insko EK, Haskal ZJ. Antiphospholipid syndrome: patterns of life-threatening and severe recurrent vascular complications. Radiology. 1997; 202(2):319-26.

6. Glacet-Bernard A, Bayani N, Chretien P, Cochard C, Lelong F, Coscas G. Antiphospholipid antibodies in retinal vascular occlusions. A prospective study of 75 patients. Arch Ophthalmol. 1994;112(6):790-5.

7. Levine JS, Branch DW, Rauch J. The antiphospholipid syndrome. N Engl J Med. 2002;346(10):752-63. Comment in: N Engl J Med. 2002;347(2):145-6; author reply $145-6$.

8. Turiel M, Sarzi-Puttini P, Peretti R, Rossi E, Atzeni F, Parsons W, et al. Thrombotic risk factors in primary antiphospholipid syndrome: a 5-year prospective study. Stroke. 2005;36(7):1490-4.

9. Ortel T. Thrombosis and the antiphospholipid syndrome. Hematology. 2005;462-8.

10. Santamaria JR, Badziak D, Barros MF, Mandelli FL, Cavallin LC, Sato MS. Síndrome Antifosfolípede. An Bras Dermatol. 2005;80(3):225-39.

11. Rosove MH, Brewer PM. Antiphospholipid thrombosis: clinical course after the first thrombotic event in 70 patients. Ann Intern Med. 1992; 117(4):303-8. 